\title{
MOLECULAR CHARACTERIZATION OF VANA-CONTAINING ENTEROCOCCUS FROM MIGRATORY BIRDS: SONG THRUSH (TURDUS PHILOMELOS)
}

\author{
Nuno Silva, ${ }^{1,2}$ Gilberto Igrejas, ${ }^{3,4}$ Ana Felgar, ${ }^{1-4}$ Alexandre Gonçalves, ${ }^{1-4}$ Rui Pacheco ${ }^{1-4}$, Patrícia Poeta ${ }^{1,2}$ * \\ ${ }^{1}$ Department of Veterinary Sciences, University of Trás-os-Montes and Alto Douro, Vila Real, Portugal; ${ }^{2}$ Veterinary and Animal \\ Science Research Centre (CECAV), Vila Real, Portugal; ${ }^{3}$ Department of Genetics and Biotechnology, University of Trás-os- \\ Montes and Alto Douro, Vila Real, Portugal; ${ }^{4}$ Institute for Biotechnology and Bioengineering, Centre of Genetics and \\ Biotechnology, University of Trás-os-Montes and Alto Douro, Vila Real, Portugal.
}

Submitted: April 30, 2011; Returned to authors for corrections: October 29, 2011; Approved: June 07, 2012.

\begin{abstract}
Vancomycin-resistant enterococci (VRE) were detected in two faecal samples $(1.3 \%)$ of song thrush in Portugal. vanA isolates showed high level vancomycin/teicoplanin resistance, as well as resistance to ciprofloxacin, quinupristin-dalfopristin and cloranfenicol. Thrush can be a reservoir of VRE and transmit these resistant bacteria to other animals including humans.
\end{abstract}

Key words: Migratory birds, vanA-containing enterococci, Antibiotic resistance; Portugal.

Enterococci are commensal bacteria of the intestinal microbiota of humans and animals. Although they are generally considered commensal bacteria, they have the potential to cause a number of infections. Multidrug-resistant enterococci have been increasingly identified as the most important pathogens responsible for nosocomial infections in humans (11). Enterococcus faecalis represents 80 to $90 \%$ of human clinical enterococcal infections, while $5 \%$ to $15 \%$ are caused by the Enterococcus faecium specie. However, other species including Enterococcus hirae and Enterococcus durans are occasionally identified in clinical isolates (18). Common enterococcal infections include those of the urinary tract, bloodstream, endocardium and wounds (19). Although relatively rare, infections with enterococci has been described in poultry $(4,5)$ and in others birds like canaries and psittacine birds $(7,8)$.
The emergence of vancomycin resistant enterococci (VRE) in Europe has been associated to the use of glycopeptides, such as avoparcin, as growth promoters in livestock (3) until its ban in 1997 in the European Union. Previous reports have demonstrated the presence of VRE in faecal samples of poultry and wild animals in different countries, including Portugal $(9,12,14)$, but no study has addressed the occurrence of VRE in migratory game birds.

The song thrush is a typical and numerous migratory bird and is one of the main game birds hunted in the Iberian Peninsula (17). As meat from these animals is traditionally consumed in some European countries such as Portugal the risk of transferring VRE strains to humans is a possibility.

The aim of the present study was to analyse the prevalence and molecular characterization of vanA-containing 
Enterococcus in faecal samples of the song thrush ( $T$. philomelos) in Portugal.

One hundred and fifty four thrushes were captured by hunting associations in the north of Portugal between November 2009 and February 2010, during the thrush hunting season. This activity is supervised by the Agriculture, Rural development and Fishery Ministry of Portugal under the Decree-Law no. 202/2004. After necropsy, faecal samples were obtained from the colon of each thrush and stored individually in plastic sterile tubes. Samples were immediately transferred to peptone water and processed with $24 \mathrm{~h}$ of receipt in the laboratory. Samples were spread in Slanetz-Bartley agar plates supplemented with $4 \mathrm{mg} / \mathrm{L}$ of vancomycin and were incubated for $48 \mathrm{~h}$ at $37^{\circ} \mathrm{C}$. Colonies with typical enterococcal morphology (four per sample) were identified by cultural characteristics, Gram-staining, catalase test, bile-aesculin reaction and by biochemical tests using the API ID20 Strep system (BioMérieux, La Balme Les Grottes, France). Furthermore, enterococci were identified to the species level by PCR using primers and conditions for the different enterococcal species (20).

Antibiotic susceptibility was tested for 11 antibiotics [vancomycin $(30 \mu \mathrm{g})$, teicoplanin $(30 \mu \mathrm{g})$, Ampicillin $(10 \mu \mathrm{g})$, streptomycin $(300 \mu \mathrm{g})$, gentamicin $(120 \mu \mathrm{g})$, kanamycin $(120$ $\mu \mathrm{g})$, chloramphenicol $(30 \mu \mathrm{g})$, tetracycline $(30 \mu \mathrm{g})$, erythromycin $(15 \mu \mathrm{g})$, quinupristin-dalfopristin $(15 \mu \mathrm{g})$, and ciprofloxacin $(5 \mu \mathrm{g})$ ] by the agar disk diffusion method as recommended by the Clinical and Laboratory Standards Institute (6). The agar dilution CLSI method was also used to determine the minimal inhibitory concentration (MIC) for vancomycin (Eli Lilly, Indianapolis, IN) and teicoplanin (Hoeschst Marion Roussell, Paris, France). E. faecalis (ATCC 29212) and Staphylococcus aureus (ATCC 25923) were used for quality control.

Vancomycin resistance genes (van $\mathrm{A}, \operatorname{van} \mathrm{B}, \operatorname{van} \mathrm{C}-1$, and vanC-2) were tested by PCR in all VRE isolates (20). Other resistance genes, erm(A) and erm(B) (in erythromycin-resistant isolates), $\operatorname{tet}(\mathrm{M})$ and $\operatorname{tet}(\mathrm{L})$ (in tetracycline-resistant isolates) $\operatorname{vat}(\mathrm{D})$ and $\operatorname{vat}(\mathrm{E})$ (in quinupristin/dalfopristin-resistant isolates), and $\operatorname{cat}(\mathrm{A})$ (in chloramphenicol-resistant isolates) were also tested by PCR in all VRE, using primers and conditions previously reported $(1,20)$. The presence of $\operatorname{Tn} 916$ and Tn5397-specific sequences was also studied by PCR in the tet(M)-positive isolates (2). Positive and negative controls were used in all PCRs, from the strain collection of the University of Trás-os-Montes and Alto Douro (Portugal). DNA sequencing was used to verify the identity of the gene products of at least one randomly selected isolate for each gene.

The present paper is the first report of vanA-containing enterococcal strains in Turdus philomelos in Portugal. Two of the 154 thrushes faecal samples tested contained vanA isolates $(1.3 \%)$ and four isolates per sample were identified to the species level and it was determined their antibiotic susceptibility profile. Two vanA isolates from each positive sample exhibited the same enterococcal species and the same antibiotic resistance profile and for this reason, only two isolates per positive sample were maintained for further studies making a collection of 4 isolates (Table 1 ).

Table 1. Characteristics of the vanA-containing Enterococcus recovered from song thrush.

\begin{tabular}{lllll}
\hline \multirow{2}{*}{ Enterococcus strain } & \multicolumn{2}{c}{ MIC $(\mathbf{m g} / \mathbf{L}) *$} & Resistant phenotype** & Genes or transposon sequences detected \\
\cline { 2 - 4 } & Vancomycin & Teicoplanin & & \\
\hline E. faecium ST41A & $>128$ & 64 & ERY; TET; QD & $\operatorname{erm}(\mathrm{B}), \operatorname{tet}(\mathrm{L})+\operatorname{tet}(\mathrm{M}), \operatorname{Tn} 916, \operatorname{Tn} 5397$ \\
E. faecium ST41B & $>128$ & 64 & ERY; TET; CIP; CHL & $\operatorname{erm}(\mathrm{B}), \operatorname{tet}(\mathrm{L})$ \\
E. hirae ST45A & $>128$ & 64 & ERY; TET; CIP & $\operatorname{erm}(\mathrm{B}), \operatorname{tet}(\mathrm{L})+\operatorname{tet}(\mathrm{M}), \operatorname{Tn} 916, \operatorname{Tn} 5397$ \\
E. durans ST45B & $>128$ & 64 & ERY; TET; CIP & $\operatorname{erm}(\mathrm{B}), \operatorname{tet}(\mathrm{L})$ \\
\hline
\end{tabular}

*MIC, minimal inhibitory concentration.

**ERY, erythromycin; QD, quinupristin-dalfopristin; TET, tetracycline; CIP, ciprofloxacin; CHL, chloramphenicol. 
The four vanA-containing enterococci isolates from song thrushes were identified as E. faecium (two isolates) E. durans and E. hirae (one isolate of each one). All van $\mathrm{A}$ isolates showed high level vancomycin (MIC > $128 \mathrm{mg} / \mathrm{l}$ ) and teicoplanin resistance (MIC $64 \mathrm{mg} / \mathrm{l})$, as well as erythromycin and tetracycline resistance. The vanA-containing enterococci isolates also showed resistance to ciprofloxacin $(n=3)$, quinupristin-dalfopristin $(n=1)$ and cloranfenicol $(n=1)$. The $\operatorname{erm}(\mathrm{B})$ gene was found in all erythromycin-resistant isolates, while the $\operatorname{tet}(\mathrm{M})$ and/or $\operatorname{tet}(\mathrm{L})$ genes were found in all tetracycline-resistant isolates being the specific sequences of Tn916 and Tn5397 transposons detected in two of them.

Although VRE is a major problem in clinics and has emerged in an important extend in different animals, as far as we know, this study is the first focused to define the prevalence of vanA-containing Enterococcus strains in $T$. philomelos. Other studies have found VRE in birds and wild animals being vanA-contining $E$. faecium and/or $E$. durans the most frequently species detected, although vanA-containing $E$. hirae was also found $(10,14-16)$.

All the vanA isolates from thrushes exhibited erythromycin resistance and it is known that erm(B) gene encoding for macrolide resistance can be carried by the same conjugative plasmid harbouring vanA gene (1). Similar results have been shown in vanA-enterococci from poultry, ostriches, buzzards and seagulls (10, 14-16). On the other hand, the association between $\operatorname{tet}(\mathrm{L})$ and $\operatorname{tet}(\mathrm{M})$ genes is very frequently reported in tetracycline-resistant enterococci isolates $(10,14-$ 16) and, in the present study, both genes was observed in two of the vanA isolates. Additionally, similar to our results, and also reported by other sudies, the tet(M) gene is usually associated with conjugative transposons related to the $\operatorname{Tn} 916$ family or to $\operatorname{Tn} 5397(2,10,13)$.

How these birds acquire VRE is unclear and one hypothesis might be that animals might be exposed to faecal material from farm animals or even from humans, taking into account that thrushes are omnivorous and migratory birds.
Human health risk from thrushes infected with VRE strains arises directly from ingestion of contaminated meat. The contamination of carcasses by feces and subsequent invasion by enteric bacteria could easily be observed in game, since, in general, after being hunted, animals are eviscerated and skinned under insufficiently hygienic conditions. VRE strains might represent a public health problem, because when infecting the urinary tract, surgical wounds or the bloodstream of hospitalized patients, it may be difficult to treat and, occasionally, can be life threatening. These results suggest that song thrush could be a reservoir of vanA-enterococci isolates and the genetic determinants of vancomycin resistance could potentially be transmitted to other bacteria of great importance in human medicine, as is the case of methicillin-resistant $S$. aureus. Moreover, this animal is a widespread resident in the North Sea region, and is partially migratory wintering in southern Europe, and thus can spread the antimicrobial resistant bacteria and their antimicrobial resistance genes throughout the environment not only locally but also among different European regions. We cannot rule out the possibility that these animals spreading fecal material across the woodland and infect other wild and farm animals or even humans. Future studies should be carried out to analyze the evolution of colonization in different ecosystems, including wild animals of different species and countries.

\section{ACKNOWLEDGEMENTS}

We thank the hunter associations of north of Portugal for their contribution to the samples collection. Nuno Silva was supported by "Programa Ciência 2008" co-financed by POPH QREN Type 4.2-Employment Promotion Scientific subsidized by the European Social Fund and National Funds of Ministry of Science for High Education (MCTES).

\section{REFERENCES}

1. Aarestrup, F.M.; Agerso, Y.; Gerner-Smidt, P.; Madsen, M.; Jensen, 
L.B. (2000). Comparison of antimicrobial resistance phenotypes and resistance genes in Enterococcus faecalis and Enterococcus faecium from humans in the community, broilers, and pigs in Denmark. Diagn. Microbiol. Infect. Dis 37: 127-137.

2. Agerso, Y.; Pedersen, A.G.; Aarestrup, F.M. (2006). Identification of Tn5397-like and Tn916-like transposons and diversity of the tetracycline resistance gene $\operatorname{tet}(\mathrm{M})$ in enterococci from humans, pigs and poultry. $J$. Antimicrob. Chemother. 57: 832-839.

3. Bager, F.; Madsen, M.; Christensen, J.; Aarestrup, F.M. (1997). Avoparcin used as a growth promoter is associated with the occurrence of vancomycin-resistant Enterococcus faecium on Danish poultry and pig farms. Prev. Vet. Med. 31: 95-112.

4. Chadfield, M.S.; Christensen, J.P.; Christensen, H.; Bisgaard, M. (2004). Characterization of streptococci and enterococci associated with septicaemia in broiler parents with a high prevalence of endocarditis. Avian Pathol. 33: 610-617.

5. Chadfield, M.S.; Christensen, J.P.; Juhl-Hansen, J.; Christensen, H.; Bisgaard, M. (2005). Characterization of Enterococcus hirae outbreaks in broiler flocks demonstrating increased mortality because of septicemia and endocarditis and/or altered production parameters. Avian Dis. 49: 16-23.

6. Clinical and laboratory standards institute (2011). Performance standards for antimicrobial susceptibility testing, Twenty First Informational Supplement M100-S21. - Clinical Laboratory Standards Institute, Wayne, PA, USA.

7. Devriese, L.A.; Chiers, K.; De Herdt, P.; Vanrompay, D.; Desmidt, M.; Ducatelle, R.; Haesebrouck, F. (1995). Enterococcus hirae infections in psittacine birds: epidemiological, pathological and bacteriological observations. Avian Pathol. 24: 523-531.

8. Devriese, L.A.; Uyttebroek, E.; Ducatelle, R.; Viaene, N.; Derijcke, J.; Gevaert, D. (1990). Tracheitis due to Enterococcus faecalis infection in canaries. J. Assoc. Avian Vet. 4: 113-116.

9. Eisner, A.; Feierl, G.; Gorkiewicz, G.; Dieber, F.; Kessler, H.H.; Marth, E.; Kofer, J. (2005). High prevalence of VanA-type vancomycinresistant Enterococci in Austrian poultry. Appl. Environ. Microbiol. 71: 6407-6409.

10. Gonçalves, A.; Poeta, P.; Silva, N.; Araujo, C.; Lopez, M.; Ruiz, E.; Uliyakina, I.; Direitinho, J.; Igrejas, G.; Torres, C. (2010). Characterization of vancomycin-resistant enterococci isolated from fecal samples of ostriches by molecular methods. Foodborne Pathog. Dis. 7: 1133-1136.
11. Huycke, M.M.; Sahm, D.F.; Gilmore, M.S. (1998). Multiple-drug resistant enterococci: the nature of the problem and an agenda for the future. Emerg. Infect. Dis. 4: 239-249.

12. Mallon, D.J.; Corkill, J.E.; Hazel, S.M.; Wilson, J.S.; French, N.P.; Bennett, M.; Hart, C.A. (2002). Excretion of vancomycin-resistant enterococci by wild mammals. Emerg. Infect. Dis 8: 636-638.

13. Poeta, P.; Costa, D.; Igrejas, G.; Rojo-Bezares, B.; Saenz, Y.; Zarazaga, M.; Ruiz-Larrea, F.; Rodrigues, J.; Torres, C. (2007). Characterization of vanA-containing Enterococcus faecium isolates carrying Tn5397-like and Tn916/Tn1545-like transposons in wild boars (Sus Scrofa). Microb. Drug Resist. 13: 151-156.

14. Poeta, P.; Costa, D.; Rodrigues, J.; Torres, C. (2005). Study of faecal colonization by vanA-containing Enterococcus strains in healthy humans, pets, poultry and wild animals in Portugal. J. Antimicrob. Chemother. 55: 278-280.

15. Radhouani, H.; Pinto, L.; Coelho, C.; Sargo, R.; Araujo, C.; Lopez, M.; Torres, C.; Igrejas, G.; Poeta, P. (2010). MLST and a genetic study of antibiotic resistance and virulence factors in vanA-containing Enterococcus from buzzards (Buteo buteo). Lett. Appl. Microbiol. 50: 537-541.

16. Radhouani, H.; Poeta, P.; Pinto, L.; Miranda, J.; Coelho, C.; Carvalho, C.; Rodrigues, J.; Lopez, M.; Torres, C.; Vitorino, R.; Domingues, P.; Igrejas, G. (2010). Proteomic characterization of vanA-containing Enterococcus recovered from Seagulls at the Berlengas Natural Reserve, W Portugal. Proteome Sci. 8: 48.

17. Rodríguez-Turienzo, L.; Díaz, O.; Sanmartín, B.; Cobos, A. (2010). Characterization of meat from two game birds: thrush (Turdus philomelos) and turtle dove (Streptopelia turtur) Caracterización de la carne de dos aves de caza: zorzal (Turdus philomelos) y tórtola (Streptopelia turtur). CYTA-J. Food 8: 209-215.

18. Ruoff, K.L.; de la Maza, L.; Murtagh, M.J.; Spargo, J.D.; Ferraro, M.J. (1990). Species identities of enterococci isolated from clinical specimens. J. Clin. Microbiol. 28: 435-437.

19. Shepard, B.D.; Gilmore, M.S. (2002). Antibiotic-resistant enterococci: the mechanisms and dynamics of drug introduction and resistance. Microbes Infect. 4: 215-224.

20. Torres, C.; Tenorio, C.; Portillo, A.; Garcia, M.; Martinez, C.; Del Campo, R.; Ruiz-Larrea, F.; Zarazaga, M. (2003). Intestinal colonization by vanA- or vanB2-containing enterococcal isolates of healthy animals in Spain. Microb. Drug Resist. 9 Suppl 1: S47-52. 